\title{
Long-Term Weight Gain and Prevalence of Obesity in General Adult Psychiatric Inpatients
}

\author{
Carlo Lazzari ${ }^{1,2,}$, Ahmed Shoka ${ }^{1}$, Basavaraja Papanna ${ }^{1}$, Marco Rabottini ${ }^{2}$ \\ ${ }^{1}$ Department of General Adult Psychiatry, Essex Partnership University NHS Foundation Trust (EPUT), Colchester, United Kingdom \\ ${ }^{2}$ Department of Statistical Modelling, International Centre for Healthcare and Medical Education (ICHME), Bristol, United Kingdom \\ Email address: \\ Carlolazzari2015@gmail.com (C. Lazzari),Ahmed.Shoka@Nhs.Net (A. Shoka),b.papanna@nhs.net (B. Papanna), \\ m.rabottini@libero.it (M. Rabottini) \\ ${ }^{*}$ Corresponding author
}

\section{To cite this article:}

Carlo Lazzari, Ahmed Shoka, Basavaraja Papanna, Marco Rabottini. Long-Term Weight Gain and Prevalence of Obesity in General Adult Psychiatric Inpatients. American Journal of Psychiatry and Neuroscience. Vol. 6, No. 3, 2018, pp. 86-94. doi: 10.11648/j.ajpn.20180603.16

Received: July 25, 2018; Accepted: August 27, 2018; Published: October 6, 2018

\begin{abstract}
Weight gain is a common concern in general adult psychiatry. However, there are no extensive and longitudinal studies to show how weight gain variates and if it does so in the inpatient population. We collected the electronic data of the weights from a sample of 186 psychiatric and non-forensic inpatients hospitalized in Essex, United Kingdom, these data being relative to a period from one to ten years. Statistical methods included the coefficient of determination $\mathrm{R}^{2}$ for progressive measures of weight, Cohen's $\mathrm{d}$ for $\mathrm{R}^{2}$, and meta-analysis to calculate the coefficient of heterogeneity $\mathrm{I}^{2}$ of individual $\mathrm{R}^{2}$ and mean weights. Subsequently, the body weights were compared with the national Body Mass Index $\left(\mathrm{BMI}=\mathrm{Kg} / \mathrm{m}^{2}\right)$. The results showed that the time variation of body weight was low to medium for male patients $\left(\mathrm{R}^{2}=0.17 ; \mathrm{d}=0.44\right)$, and medium to high for female patients $\left(\mathrm{R}^{2}=0.27 ; \mathrm{d}=0.74\right)$. Additionally, the average BMI for female patients was $31.21(\mathrm{SD}= \pm 7.73)$ corresponding to the WHO Class I Obesity spectrum while for males it was $27.05(\mathrm{SD}= \pm 5.92)$ corresponding to the WHO Overweight Class spectrum. In conclusion, overweight in males and obesity in females are commonly found in psychiatric non-forensic inpatients. However, in our study, only $27 \%$ of the females' and $17 \%$ of the males' variation in body weight was explained by the time variable. Consequently, one conclusion is that increased BMI might be comorbid with psychiatric disorders although the direction of the reciprocal influence should be investigated.
\end{abstract}

Keywords: Psychiatry, Inpatients, Body Mass Index, Obesity, Weight-Gain, Meta-Analysis, Borderline Personality Disorder

\section{Introduction}

Obesity is positively correlated with mental health illnesses [1]. In particular, the prevalence for overweight and obesity in psychiatric inpatients reaches $66 \%$ with the trend for female patients to increase their weight along with their admissions compared to males who usually reach a steady state [2]. A study by Public Health England indicates a higher rate of obesity in psychiatric patients accounting for $80 \%$ with a high risk of becoming obese when patients are detained in psychiatric hospitals [3].

In the United Kingdom, a survey by the National Obesity Observatory and the National Health Service summarizes several types of researches indicating a 'bidirectional influence' where obesity can lead to mental illness or where mental illness can lead to obesity [4].

Overall, we hypothesized four theories linking weight-gain to mental health. The first theory assumes that physical inactivity and lifestyle of psychiatric patients justifies their high BMI (Body Mass Index) [5, 6]. The second theory assumes that psychotropic medication is responsible for weight gain, especially antipsychotic medication and antidepressants of the SSRI (Serotonin System Reuptake Inhibitor) $[7,8]$. Some authors propose a combination of these factors where patients reduce physical activity, and via psychotropic medication and increased appetite acquire more weight due to some predilection for carbohydrates [9]. The third theory assumes that some type of food is responsible for psychiatric problems, mainly an increased consumption of fast food and baked goods might be conducive to depression [10]; studies in mice show a central inflammatory effect of a 
high-fat diet [11]. The fourth theory assumes that pathological weights are comorbid to psychiatric illnesses especially in female patients $[12,13]$. In fact, the prevalence of women with borderline personality disorder in the general adult inpatient population [14], and the association between borderline personality disorder and obesity [15] can partly explain why pathological weight is mostly found in the female psychiatric population with personality disorders. Furthermore, a general association has been discovered between overweight, metabolic syndrome and psychiatric illnesses [16].

However, there are no extensive and longitudinal studies to show if weight gain is already present when patients access psychiatric services or if, instead, it could be attributed to the above-mentioned theories. In the United Kingdom, data relative to psychiatric patients, including weight, are commonly recorded on an electronic database. Consequently, longitudinal data collection using electronic support can improve research outcomes [17]. Electronic medical records (EMR) offer a chance for useful and extensive scientific research in psychiatry [18]. Preliminary research from the authors of the current study by using a combination between EMR and longitudinal meta-analysis suggests comorbidity between obesity and psychiatric illnesses; the hypothesis is that weight gain does not decrease during the years although extensive policies already exist in the United Kingdom to reduce obesity in psychiatric patients $[19,20]$.

Research that has investigated the effect of obesity on brain suggest that increased body weight is associated with a reduced brain size of the hippocampus, frontal and parietal lobes [21]. Compared to healthy population, persons with obesity show reduced volumes of the gray matter (frontal, temporal gyri, thalamus, and hippocampus) and white matter (internal capsule and optic radiation) [22].

A study involving 896 Chinese patients discovered that obesity was associated with decreased cognitive functioning while patients with obesity and schizophrenia had worse scores compared to patients who were not obese [23]. One systematic review found that the most altered cognitive functions in obesity are psychomotor performance and speed, and time underestimation [24].

Another study confirms the co-occurrence of factors increasing body weight in the psychiatric inpatients like raised sleep hours, smoking, incorrect diets, antipsychotic medication although the same research did not find a correlation between weight change and length of admission [25]. Although specific programs exist in the United Kingdom to reduce metabolic syndrome in psychiatric inpatients their effectiveness is considered low. For instance, although the most adopted measures to counteract weight-gain in psychiatric inpatients are diet guidance, sports syllabi, fitness awareness groups, open gym, walks, and bicycle outdoors, one study evidenced that these programs were only modestly effective in $55 \%$ and ineffective in $25 \%$ of cases [26].

Previous studies by the same authors of the current research show a prevalence of females with borderline personality disorder in the adult psychiatric inpatients hence suggesting that this target population might be the one with the highest number of observations of severe overweight and obesity [14, 20]. One study seems to confirm the hypothesis suggesting that difficulties in controlling impulsive eating might be responsible for obesity in psychiatric inpatients [27].

Regarding age, one study found no correlation between weight gain and age of patients who instead, show a correlation of psychotropic medication with hypertension and diabetes [28].

Regarding the use of psychotropic medication which is known to increase weight, some are also responsible for the increased incidence of diabetes type 2 and hypertension, for instance, olanzapine [29]. Adverse metabolic syndrome and most notably diabetes type 2 have been associated with the second-generation antipsychotics (SGAs) especially olanzapine and clozapine [30]. However, one hypothesis suggests that the glucose-metabolism dysregulation and hyperinsulinemia by clozapine and olanzapine are also correlated to higher antipsychotic action; therefore, it is hypothesized that the therapeutic and metabolic effects might be concordant and acted on insulin brain receptors [31]. Patients identified at higher risk are older females with unipolar depression and bipolar disorder [32, 33].

Under broader perspective, obesity itself is associated to a higher frequency of hospitalizations in studies reporting the prevalence in different countries and a similar prevalence in general medical wards and psychiatric wards, with an average BMI for males and females of $25.4 \mathrm{Kg} / \mathrm{m} 2$ [34]. However, hospitalized patients with obesity might reflect the same prevalence of obesity affecting the population of the same catchment area. In the UK, a National Health Service survey discloses that in $2015,58 \%$ of women and $68 \%$ of men resulted to be overweight or obese, while two out of three admissions had a primary diagnosis of obesity, and $74 \%$ were females [35].

Our recent research indicates a prevalence of admissions in general adult psychiatric wards of females of white ethnic background with borderline personality disorder [14]. These patients have already high prevalence of severe obesity [36]. A study in the United States found a prevalence of borderline personality disorder in $26.9 \%$ of the obese population linking personality disorder to compulsive eating [15]. A study indicates that child abuse in females is associated with obesity later in life [37].

Research also associates obesity with depression. For instance, compared to adolescents with healthy BMI, obese adolescents have a higher incidence of cognitive and psychiatric problems, comprising poor records at the school, low self-esteem, depression, and a higher rate of suicide attempts [38]. In general, major depressive disorder (MDD) has been associated with a higher risk of obesity probably linked to increased appetite and sleep time [39]. An association between obesity and recurrent depression has been associated to lower hippocampal volume [40].

Disturbances in metabolism and obesity are present in subjects with psychosis autonomously from psychotropic medication [41]. Furthermore, overweight and obesity might be conducive to brain alterations already in the initial stages of 
psychosis [42]. The hypothesis is that high BMI causes alteration of the cerebral white matter in schizophrenia by hindering the neurotransmission in the cortico-limbic networks which play a crucial role in neurocognition, emotions, and mental health in schizophrenia [43].

Research has also found an association between obesity and bipolar disorder sharing the same causes together with the obesogenic action of mood stabilizers [44]. Another study found that increased BMI is related to the size of the frontal cortical lobes in adolescents with bipolar disorder [45]. Overall research shows an association of obesity with the schizoaffective disorder characterized by a history of major depressive disorder and suicide attempts [46].

The current research will address the long-term changes in weight gain and the prevalence of obesity in the general adult psychiatric inpatients. The aim is to verify if weight gain is associated or not with circumstances that are present and predictable in psychiatric wards as affecting weight, like psychotropic medications, reduced physical activity or poor eating habits, or if data would instead suggest comorbidity between increased BMI and mental health.

\section{Material and Methods}

This current research is a perspective and cross-sectional study. Electronic data for body weights relative to a period from one to ten years were collected for 186 psychiatric inpatients in the general adult population (99 males and 87 females) with the average age for males of 39.65 years $(\mathrm{SD}=$ $\pm 11.66)$ and females of 40.88 years $(\mathrm{SD}= \pm 13.73)$.

Data refer to the non-forensic inpatients in general adult psychiatric wards in Essex, United Kingdom. Statistical methods included the coefficient of determination $\mathrm{R}^{2}$ computing the time-variation of body weight, Cohen's d effect size for the $\mathrm{R}^{2}$, and the heterogeneity factor $\mathrm{I}^{2}$ from exploratory meta-analysis measuring differences in individual $\mathrm{R}^{2}$ and variances in the average weights. The Body Mass Index (BMI) was calculated by utilizing the national parameters for the height of the male $(175.3 \mathrm{~cm})$ and female $(161.6 \mathrm{~cm})$ population in the United Kingdom as from the Office for National Statistics [47].

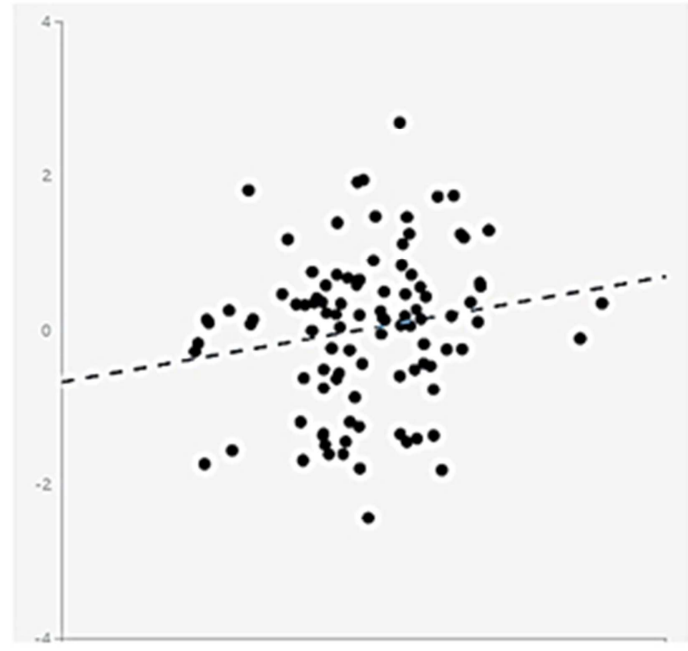

Exclusion criteria in the correlation studies where patients presenting with less than three weight observations. Statistical packages included Medcalc [48] and Open Meta-analyst [49]. We used the National Health Service BMI Calculator [50]. The statistical triangulation involved a sequential mixed design [51], mixed methods [52] and longitudinal transformation [53] because data were collected via following and multiple quantitative methods that were implemented at separate times and then integrated at the end of the term using exploratory meta-analysis.

Meta-analysis is a robust statistical method; it can overcome the restrictions posed by small-sample studies by summarizing the results of distinct studies to produce the single best estimation and increasing the generalizability of the results $[54,55,56]$. We used exploratory meta-analysis applied to BMI and $\mathrm{R}^{2}$ [57]. Furthermore, meta-analysis can be used to calculate the effect of independent variables on experimental outcomes [58,59] or gather the results of observations that occur at different times [60], as in the current research. In the current research, meta-analysis was applied to measure the coefficient of heterogeneity $\mathrm{I}^{2}$ within measures.

Longitudinal data were computed by using the coefficient of determination $\mathrm{R}^{2}$ (Figure 1). $\mathrm{R}^{2}$ measures the proportion of variation of the dependent variable (weight gain) justified by the variation of the independent variable or predictor (time) [61]. In our case, R2 also has a predictive meaning as it allows for the extrapolation of the correlation curve and makes some estimate on probable future behaviors of the dependent variable (weight).

In the current research, patients' weight readings were collated into a spreadsheet which automatically converted subsequent readings into $R^{2}$ values. Once each patient's $R^{2}$ was obtained it entered the meta-analysis to verify if $R^{2}$ showed heterogeneity in the whole population. Weights were usually taken every week and could be found in the electronic records since the actual system was introduced in Essex, meaning about ten years ago. Similarly, $\mathrm{R}^{2}$ can also have a graphic representation which explores the overlapping of the observed data with the hypothetical curve for a perfect correlation also expressed as shared variance (Figure 1) [62].

\section{Correlation: 0.17}

Sample size $100 \quad$ New somple

Shared variance: $2.9 \%$

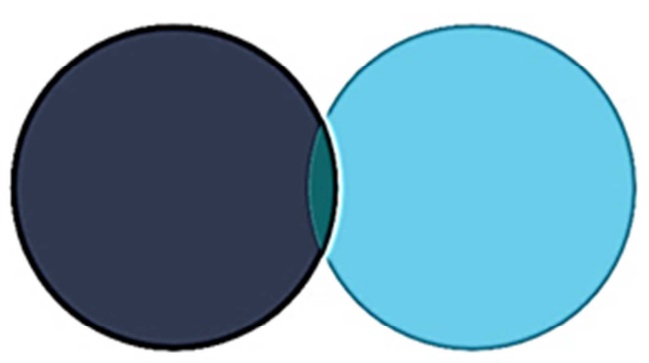



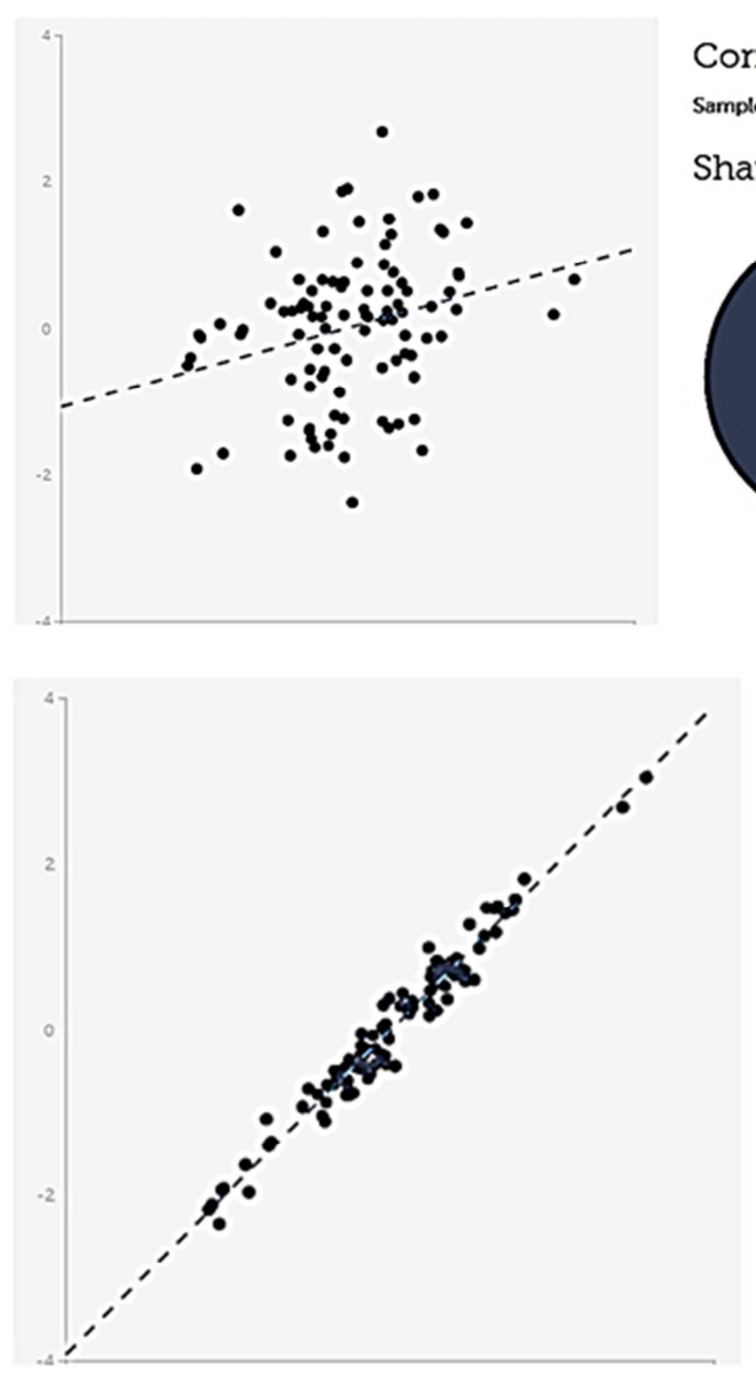

\section{Correlation: 0.27}

Sample size $100 \quad$ New somple

\section{Shared variance: $7.3 \%$}

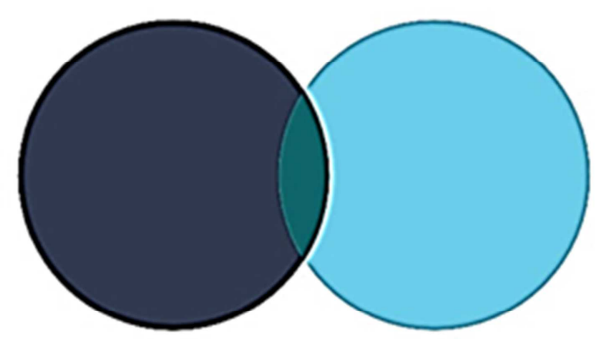

\section{Correlation: 0.98}

Sample size $100 \quad$ Newsomole

\section{Shared variance: $96 \%$}

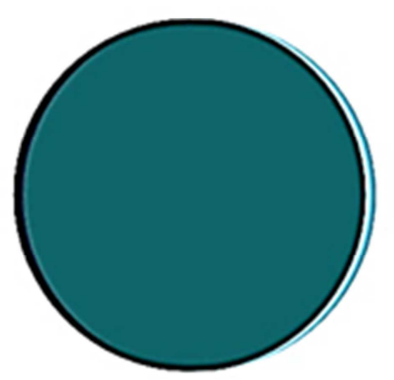

Figure 1. Statistical modeling of $R 2$ with values obtained from the results with 22 of 0.17 (males), 0.27 (females) and the hypothetical optimal correlation of $R 2=0.98$. The shared variances between the points of the observed data and the hypothetical curve are 2.9\% (males) and $7.3 \%$ (females) compared to the hypothetical shared variance of $96 \%$ when the observed data overlap the hypothetical curve for a perfect correlation [62].

Cohen's d individual and global effect sizes were calculated using online effect size calculators [63, 64]. Intermediate effect size is for values above 0.5 and high for values above 0.8 [65]. The visualization of Cohen's $d$ [66] allows defining how the group under observation diverges from the hypothetical population with low values of $d$ suggesting a significant overlap between the two curves.
For instance, with Cohen's $d=0.4$ the two curves overlap for $85.15 \%$, while $66 \%$ of the treatment group will be above the mean of the control group (Cohen's U3); instead with Cohen's $d=0.7$ the two curves overlap on for the $72.63 \%$ while $76 \%$ of the treatment group will be above the mean of the control group (Cohen's U3) (Figure 2) [66].

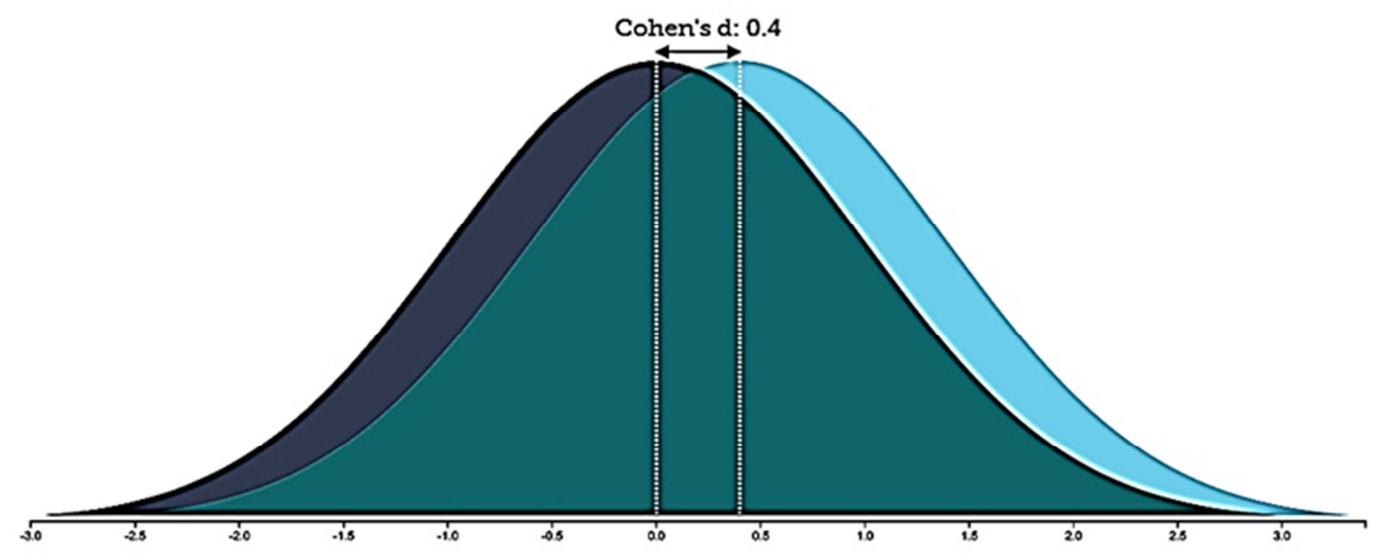



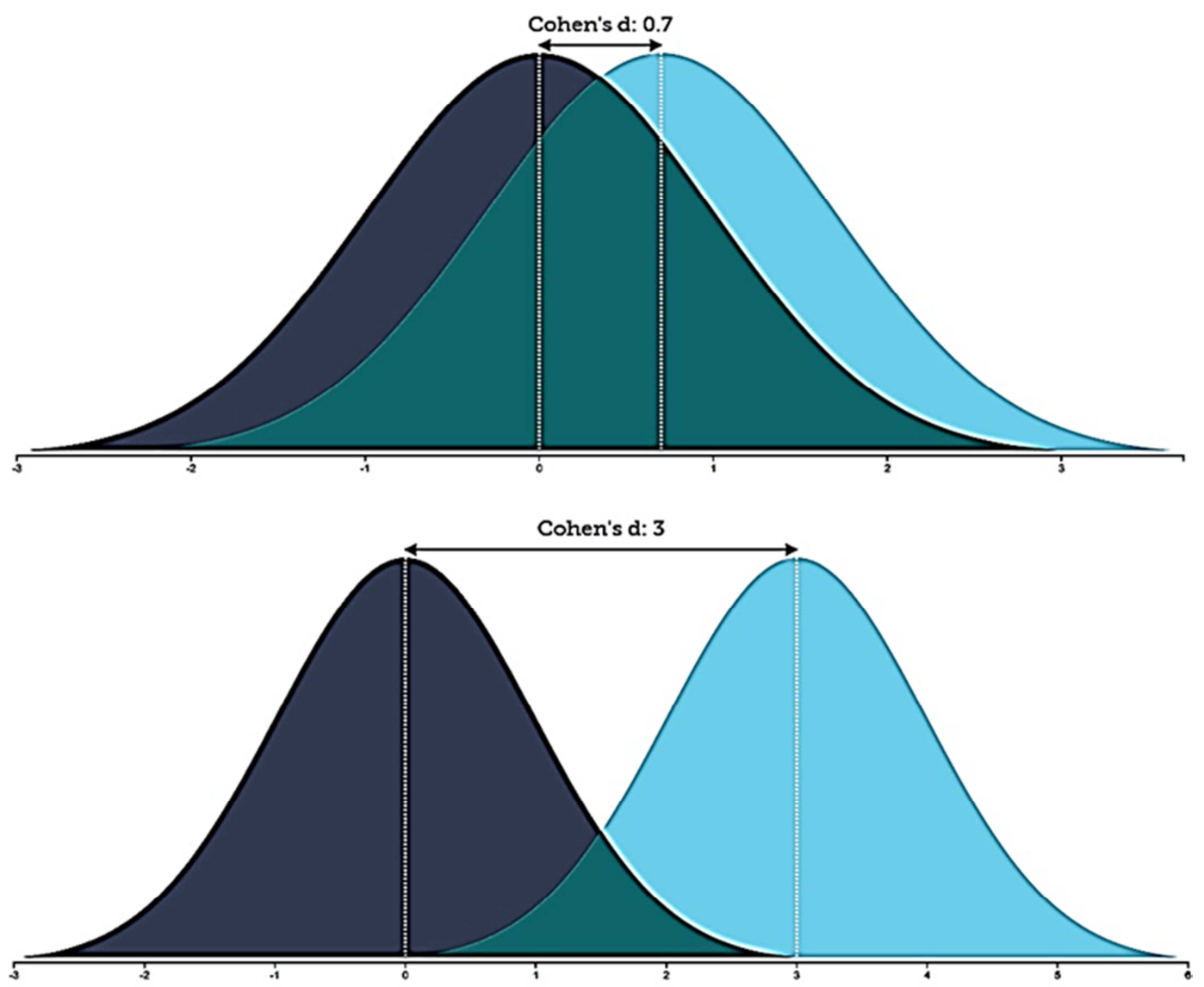

Figure 2. Statistical modelling of Cohen's $d$ showing the degree of overlap between the experimental curve (ighter color) and the normal curve (darker color) $d=0.4$ (above) [ $R^{2}$ for males] and $d=0.7$ (center) [ $R^{2}$ for females] and hypothetical $(d=3)$. At $d=0$ there is no difference between the two curves that will overlap completely [66].

Finally, with the hypothetical Cohen's d=3.0, $100 \%$ of the treatment group will be above the mean of the control group (Cohen's U3) indicating that the experimental group is affected by the variable under investigation, in our case body weight changing according to the variable time [66]. Hence, the higher the effect size (Cohen's d) the wider is the difference between the experimental group (the one observed) and a hypothetical population where the effect of the variable under investigation, weight gain/time, is assumed to be nil.

BMI is categorized according to World Health Organization (WHO) international classification which classifies 'underweight' with BMI less than 18.5, 'healthy weight' with BMI between 18.5 and 24.9, 'overweight' with BMI between 25 and 29.9, 'obesity class I' with BMI between 30 and 34.9, 'obesity class II' with BMI between 35 and 39.9, and 'obesity class III' with BMI from 40 and over [67, 68].

When results were provided as percentages, the online statistical program Medcalc [48] calculated the significance for differences of proportions or a single proportion. In this last case, the Null Hypothesis (Ho) was obtained by dividing $100 \%$ by the number of entries in the results. For instance, in Table 3, the results were compared with $\mathrm{Ho}=20 \%(100 \div 5)$. In general, weight gain is defined as a growth of $7 \%$ or more of the weight from the starting point till to the endpoint [69].

The current research was conducted according to the conventions of the Declaration of Helsinki principles of 1975, as revised in 2008. The electronic data related to patients were gender, age, and weight. Data were stored in encrypted files accessible only to the clinicians involved in the research. The anonymity of patients was maintained at all stages of the research.

\section{Results}

Some of the results were graphically commented in the Methods (Figures 1 and 2). Regarding the time variation of body weight, mean $\mathrm{R}^{2}$ for male patients $(\mathrm{n}=90)$ was 0.17 $(95 \% \mathrm{CI}=0.14-0.20)$, Cohen's $\mathrm{d}=0.44$ (small), and the coefficient of heterogeneity $\mathrm{I}^{2}$ was $91.52 \%(\mathrm{p}<0.001)$. For female patients $(\mathrm{n}=48)$ mean $\mathrm{R}^{2}$ was $0.27(95 \% \mathrm{CI}=$ $0.20-0.34$ ), Cohen's $d=0.74$ (intermediate), and the coefficient of heterogeneity $\mathrm{I}^{2}=72.26 \%(\mathrm{p}<0.001)$.

Furthermore, the meta-analysis revealed statistically significant heterogeneity in males' body weight $(n=99)$, with a mean weight of $83.33 \mathrm{Kg}(95 \% \mathrm{CI}=80.03-86.63)$, coefficient of heterogeneity $\mathrm{I}^{2}=99.86 \%(\mathrm{p}<0.01)$ and BMI of $27.1 \mathrm{Kg} / \mathrm{m}^{2}$ corresponding to the WHO overweight spectrum (Table 1 and 2). When all the BMI from every single male patient were averaged, the resulting score was instead 27.05 ( $\mathrm{SD}= \pm 5.92)$ corresponding to WHO Overweight Class (Table 3).

In females' body weight $(\mathrm{n}=87)$, the meta-analysis 
revealed statistically significant heterogeneity with a mean weight of $79.97 \mathrm{Kg}(95 \% \mathrm{CI}=79.27-80.68)$, the coefficient of heterogeneity $\mathrm{I}^{2}=99.95 \%(\mathrm{p}<0.01)$, and BMI of $31.9 \mathrm{Kg} / \mathrm{m}^{2}$ corresponding to the WHO obese spectrum (Table 1 and 2). When all the BMI from every single female patient were averaged, the resulting score was instead $31.21(\mathrm{SD}= \pm 7.73)$ corresponding to WHO Obesity Class I (Table 3 ).

The next step was to count the number of male and female patients showing pathological BMI (Table 3). When each single patient BMI was calculated (Table 3), it emerged a prevalence of healthy weight in males $(\mathrm{N}=100 ; 44 \%)$ and overweight in females $(\mathrm{N}=81 ; 29.62 \%)$. BMI evenly distributed in all classes for females while concentrating on overweight for males (Table 3). Overall, the BMI of the female population tends to be higher than the BMI in the male population and more dispersed within all BMI categories (Figure 3).

Table 1. Longitudinal data and $R^{2}$.

\begin{tabular}{|c|c|c|c|c|c|}
\hline Gender & $\mathbf{N}$ & Cohen's d & $\mathbf{R}^{2}$ & $\mathbf{I}^{2}$ & p-value \\
\hline Males & 90 & 0.44 & 0.17 & $91.52 \%$ & $p<0.001$ \\
\hline Females & 48 & 0.74 & 0.27 & $72.26 \%$ & $p<0.001$ \\
\hline
\end{tabular}

Table 2. Average weights and BMI

\begin{tabular}{lllll}
\hline Gender & N & BMI & I2 & \\
\hline Males & 99 & 27.1 & $98.86 \%$ & p-value \\
Females & 87 & 31.9 & $99.95 \%$ & p $<0.001$ \\
\hline
\end{tabular}

Table 3. Number of patients with pathological BMI and percentages, Z scores, and Cohen's d. Null Hypothesis (Ho) for percentages calculated at 20\%.

\begin{tabular}{|c|c|c|c|c|c|}
\hline Gender & Healthy weight & Over-weight & Obesity Class I & Obesity Class II & Obesity Class III \\
\hline Males $(n=100)$ & $44 \%$ & $29 \%$ & $17 \%$ & $4 \%$ & $4 \%$ \\
\hline p-values & $<0.001$ & 0.02 & n.s. & $<0.001$ & $<0.001$ \\
\hline $\mathrm{Z}$ & 0.77 & 1.05 & 1.37 & 2.05 & 2.05 \\
\hline Females $(n=81)$ & $22.22 \%$ & $29.62 \%$ & $13.58 \%$ & $19.75 \%$ & $14.81 \%$ \\
\hline p-values & n.s. & 0.02 & n.s. & n.s. & n.s. \\
\hline $\mathrm{Z}$ & 1.22 & 1.04 & 1.49 & 1.28 & 1.44 \\
\hline Differences between percentages & $21.78 \%$ & $0.62 \%$ & $3.42 \%$ & $15.75 \%$ & $10.81 \%$ \\
\hline p-values for differences & $<0.01$ & n.s. & n.s. & $<0.001$ & 0.01 \\
\hline
\end{tabular}

BMI IN MALE AND FEMALE POPULATION

BMIM D BMIF

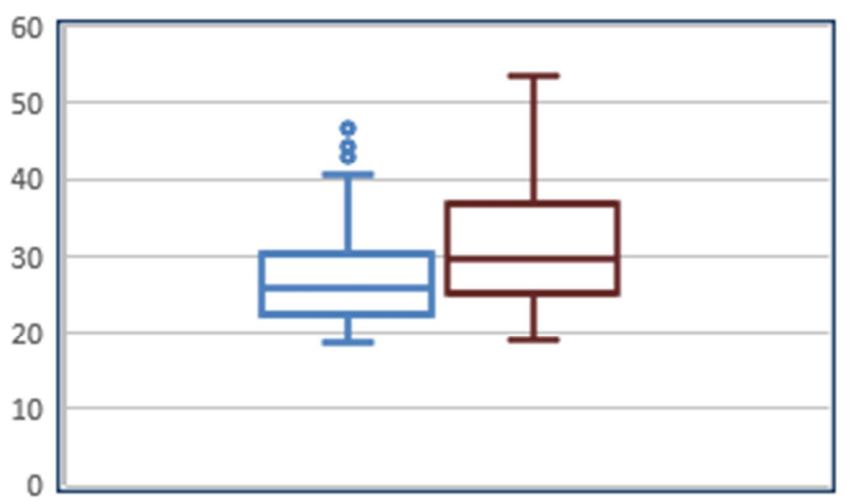

Figure 3. Boxplots for the global BMI of the female psychiatric inpatients (BMIF) shows global higher values than the BMI in the male psychiatric inpatients (BMIM). In the female population, the average BMI is higher than males'values while the BMI scores are more dispersed than in the male population. The average females' BMI (31.21) is higher than the average males' BMI (27.05).

\section{Conclusions}

Overweight in males and obesity in females were found in psychiatric inpatients of our sample. Moreover, a progressive weight gain is more significant in female than male patients during their admissions although individual variations were higher in male than female patients. However, in our sample, only $27 \%$ in females' and $17 \%$ in males' variation in body weight was explainable by the time variable. Significant heterogeneity was similarly found in the average weights both for male and female patients.

Therefore, in our study, no significant changes in body weight were found during long-term admissions although psychiatric hospitals in the UK have been implementing programs in improving body weight in psychiatric inpatients. For instance, many hospitals have clear policies in the wise selection of psychotropic medication that could affect body weight. Other hospitals also offer regular physical activities to inpatients to improve their pathological BMI.

Therefore, one conclusion is that the metabolic syndrome and, therefore, increased BMI, overweight, and obesity are co-morbid with psychiatric illnesses and might thus be difficult to treat. These findings would confirm the hypothesis of the association between obesity and mental health suggesting a mutual influence.

In any case, a radical change of habits in the psychiatric population is desirable to reduce the impact that a metabolic syndrome triggered by pathological BMI becomes a high concern in the general adult psychiatric population. Research shows that increased BMI is linked to reduced brain size with 
axonal/myelin anomalies in the white matter, with a reduction in the gray matter, and with consequent damage to neurons [70]. Preliminary studies in mice show that diets high in fat alter the mice's intestinal microbiome while disturbing their neuro-behavior including increased anxiety, abnormal behavior and reduced memory [11].

One suggestion proposed to overcome these effects is the use of non-steroidal anti-inflammatory drugs and $\omega-3$ fatty acids to promote the growth of helpful intestinal bacteria in patients at risk of high BMI and psychiatric disorders [71] thus having beneficial effects on mental health [72]. Additionally, the reluctance of psychiatric teams to change medications that have shown benefits for some patients might strengthen the use of those psychotropic drugs that mostly affect body weight.

Moreover, although policies for physical activities exist and are promoted, limited physical spaces in psychiatric wards and rare gyms make obesity epidemic in psychiatric inpatients. Lastly, many patients use comfort eating and energy food to deal with anxieties or increased drowsiness, and this behavior would make obesity comorbid but not cause of mood disorders. The use of energy drinks is commonly found as patients try to balance over-sedation from medication. Additionally, people who are unemployed and socially isolated do not use outdoor activities; in this case, obesity will ensue as a lifestyle in those who already suffer from minimal mental health problems.

Therefore, low socioeconomic status, often leading to depression and hopelessness, will favor the use of junk food, highly caloric and fat food making obesity a common finding especially in females with borderline personality disorder and depression coming from underprivileged social classes.

Furthermore, the observations that links the current research with previous studies from the same authors is that the group of the psychiatric inpatients that is mostly affected by obesity is the borderline female patients who might use impulsive eating to soothe emotional turmoil or as a form of self-harm, but also linked to other forms of eating disorders like anorexia and bulimia. Besides, in the United Kingdom, as most of the female patients with borderline personality disorder come from Children and Adolescent Mental Health Services (CAMHS), the process of weight gain might have started earlier, while it is registered once these adolescents, having reached the age of 18 , become inpatients in adult wards.

The current study shows several limitations. One weakness is that the entry and exit weight of the population could have shown higher variations than the longitudinal study. Besides, when first becoming inpatients the sample might already have started to assume psychotropic medication that affects body weight then recorded at the first admission. Furthermore, a vicious circle might link low self-esteem, comfort eating and depression giving the false impression of comorbidity where eating can also be used as a self-harming behavior in female patients with borderline personality disorder.

Therefore, further research is needed to verify if pathogenic factors act individually or consensually in psychiatric inpatients thus suggesting a multifactorial cause for pathological weight-gain. Preliminary research indicates that given the association of high BMI and depression, an improved metabolic state through the normalization of obesity shall have effects also on the underlying depression [73].

\section{Acknowledgements}

The authors acknowledge the nurses and personnel of Essex Partnership Trust who collected the body weight and BMI of the sample reported.

\section{Conflict of Interest}

The authors declare no conflicts of interest concerning the authorship and publication of this article.

\section{References}

[1] Lin HY, Huang CK, Tai CM, Lin HY, Kao YH, Tsai CC, Hsuan CF, Lee SL, Chi SC, Yen YC. Psychiatric disorders of patients seeking obesity treatment. BMC Psychiatry, 2013, 13(1):1-8.

[2] Long C, Rowell A, Gayton A, Hodgson E, Dolley O. Tackling obesity and its complications in secure settings. Mental Health Review Journal, 2014; 19(1):37-46.

[3] Day M, Maxine J. Working together to address obesity in adult mental health secure units. A systematic review of the evidence and a summary of the implications for practice. London: Public Health England, 2017. Available:

https://www.gov.uk/government/publications/obesity-in-ment al-health-secure-units.

[4] Gatineau M., Dent M. Obesity and mental health. Oxford: National Obesity Observatory and National Health Service (NHS) 2011. Available:

https://www.scie-socialcareonline.org.uk/obesity-and-mentalhealth/r/a11G00000017trJIAQ

[5] Lopresti AL, Drummond PD. Obesity and psychiatric disorders: Commonalities in dysregulated biological pathways and their implications for treatment. Prog Neuropsychopharmacol Biol Psychiatry, 2013; 45:92-99.

[6] Hilton NZ, Ham E, Lang C, Harris TG. Weight gain and its correlates among forensic inpatients. CJP, 2015; 60(5):232-238.

[7] Gebhardt S, Haberhausen M, Heinzel-Gutenbrunner M, Gebhardt N, Remschmidt H, Krieg JC, Hebebrand J, Theisen FM. Antipsychotic-induced body weight gain: Predictors and a systematic categorization of the long-term weight course. Antipsychotic-induced body weight gain: Predictors and a systematic categorization of the long-term weight course. J Psychiatr Res, 2009; 43(6):620-626.

[8] Uguz F, Sahingoz M, Gungor B, Aksoy F, Askin R. Weight gain and associated factors in patients using newer antidepressant drugs. Gen Hosp Psychiatry, 2015; 37(1):46-48.

[9] Küçük L, Kaya H, Çömez T, Kaçar S, Kutlu Y, Zülfikar H. Eating behaviors and related factors in psychiatric patients. Arch Psychiatr Nurs, 2018; 32(2):194-199. 
[10] Sánchez-Villegas A, Toledo E, de Irala J, Ruiz-Canela M, Pla-Vidal J, and Martínez-González. Fast-food and commercial baked goods consumption and the risk of depression. Public Health Nutr, 2012; 15(3):424-432.

[11] Bruce-Keller AJ, Salbaum MJ, Luo M, Blanchard IV E, Taylor CM, Welsh DA, Berthoud H-R. Reply to: High-fat diet-induced dysbiosis as a cause of neuroinflammation. Biol Psychiatry, 2016; 80: e5-e6.

[12] Sholtz S, Morgan JF. Obesity and psychiatry. Psychiatry, 2009; 8(6):198-202.

[13] Dickerson FB, Brown CH, Kreyenbuhl JA, Fang L, Goldberg RW, Wohlheiter K, Dixon LB. Obesity among individuals with serious mental illness. Acta Psychiatr Scand, 2006; 113(4): 306-313.

[14] Lazzari C, Shoka A, Papanna B, Kulkarni K. Predominant diagnoses, gender, and admission duration in an adult psychiatric inpatient hospital in United Kingdom. OJPAS, 2017; 9(1):37-40.

[15] Sansone RA, and Sansone LA. The relationship between borderline personality and obesity. Innov Clin Neurosci, 2013; 10(4):36-40.

[16] Rajan TM, and Menon V. Psychiatric disorders and obesity: A review of association studies. JPGM, 2017; 63(3):182-190.

[17] Udtha M, Nomie K, Yu E, Sanner J. Novel and emerging strategies for longitudinal data collection. J Nurs Scholarsh, 2015; 47(2):152-160.

[18] Perlis RH, Iosifescu DV, Castro VM, Murphy N, Gainer VS, Minnier $\mathrm{J}$, et al. Using electronic medical records to enable large-scale studies in psychiatry: treatment resistant depression as a model. Psychol Med, 2012; 42(1):41-50.

[19] Lazzari C, Shoka A, Mousailidis G, Papanna B. Meta-analysis of long-term weight gain in general adult psychiatric inpatients [version 1; not peer reviewed]. F1000Res, 2017; 6:2014 (slides) (doi: 10.7490/f1000research.1115085.1).

[20] Lazzari C., Shoka A., Papanna B, Mousalidis G. Long-Term weight gain in psychiatric inpatients: A Meta-Analysis. Proceedings of the 27th European Congress of Psychiatry (EPA), Nice, 2018, Eur Psychiat, 2018; 48:PW0847.

[21] Hidese S, Ota M, Matsuo J, Ishida I, Hirashi M, Yoshida S, et al Association of obesity with cognitive function and brain structure in patients with major depressive disorder. $J$ Affect Disorders, 2018; 225:188-194.

[22] Monda V, La Marra M, Perrella R, Caviglia G, Iavarone A, et al. Obesity and brain illness: from cognitive and psychological evidences to obesity paradox. Diabetes, Metabolic Syndrome and Obesity: Targets and Therapy 2017; 10:473-479.

[23] Guo X, Zhang Z, Wei Q, Lv H, Wu R, Zhao J. The relationship between obesity and neurocognitive function in Chinese patients with schizophrenia. BMC Psychiatry, 2013; 13(109):1-6.

[24] Prickett C, Brennan L, Stolwyk R. Examining the relationship between obesity and cognitive function: A systematic literature review. Obes Res Clin Pract, 2015; 9:93-113.

[25] Huthwaite M, Elmslie J, Every-Palmer S, Grant E, Sarah Romans SE. Obesity in a forensic and rehabilitation psychiatric service: a missed opportunity? Journal of Forensic Practice, 2017; 19(4):269-267.
[26] Haw C, and Jean Stubbs J. What are we doing about weight management in forensic psychiatry? A survey of forensic psychiatrists. The British Journal of Forensic Practice, 2011; 13(3):183-190.

[27] Deux N, Schlarb AA, Martin F, Holtmann M, Hebebrand J, Legenbauer T. Overweight in adolescent, psychiatric inpatients: A problem of general or food-specific impulsivity. Appetite, 2017; 112: 157-166.

[28] Kisely S, Cox M, Campbell LA, Cooke C, Gardner D. An epidemiologic study of psychotropic medication and obesity-related chronic illnesses in older psychiatric patients. CJP, 2009; 54(4):269-274.

[29] Kisely S, Cox M, Campbel LA, Cooke C, Gardner D. An epidemiologic study of psychotropic medication and obesity-related chronic illnesses in older psychiatric patients. Can J Psychiatry, 2009; 54(4):269-274.

[30] Hirsch L, Yang J, Bresee L, Jette N, Patten S, Pringsheim T. Second-generation antipsychotics and metabolic side effects: A systematic review of population-based studies. Drug Saf. 2017; 40(9):771-781.

[31] Raben AT, Marshe VS, Chintoh A, Gorbovskaya I, Müller DJ, Hahn MK. The complex relationship between antipsychotic-induced weight gain and therapeutic benefits: A systematic review and implications for treatment. Front. Neurosci., 2018; 11:Art 741.

[32] Hussain T, Margoob MA, Shoib S, Shafat M, Chandel KR. Prevalence of metabolic syndrome among psychiatric inpatients: A hospital-based study from Kashmir. Journal of Clinical and Diagnostic Research, 2017; 11(6):VC05-VC08

[33] Santini I, Stratta P, D'onofrio S, De Laurentis I, Santarelli V, Pacitti F, Rossi A. The metabolic syndrome in an Italian psychiatric sample: a retrospective chart review of inpatients treated with antipsychotics. Riv Psichiatr 2016; 51(1):37-42.

[34] Følling IS, Kulseng B., HelviK A-S. Overweight, obesity and related conditions: a cross-sectional study of adult inpatients at a Novergian hospital. BMC Research Notes 2014, 7(115):1-6.

[35] National Health Service Digital (NHS Digital). Statistics on obesity, physical activity and diet. 2017. Available: https://assets.publishing.service.gov.uk/government/uploads/s ystem/uploads/attachment_data/file/613532/obes-phys-acti-di et-eng-2017-rep.pdf.

[36] Powers AD, Oltmanns TF. Borderline Personality pathology and chronic health problems in later adulthood: The mediating role of obesity. Personal Disord, 2013; 4(2):152-159.

[37] Danese A, Tan M. Childhood maltreatment and obesity: systematic review and meta-analysis. Mol Psychiatr, 2014, 19:544-554.

[38] Nemiari D, Shim R, Mattox G, Holden K. The relationship between obesity and depression among adolescents. Psychiatr Ann, 2012; 42(8):305-308.

[39] Polanka BM, Vrany EA, Patel J, Stewart JC. Depressive disorder subtypes as predictors of incident obesity in US adults: Moderation by race/ethnicity. Am $J$ Epidemiol. 2017; 185(9):734-742.

[40] Nigatu YT, Bültmann U, Reijneveld SA. The progressive association between obesity and major depression in the general population: does single or recurrent episode matter? BMC Public Health, 2015; 15(350):1-8. 
[41] Orešič M. Obesity and psychotic disorders: uncovering common mechanisms through metabolomics. Dis Model Mech 2012; 5(5):614-620.

[42] Kolenic M, Frankec K, Hlinka J, Matejka M, Capkova J, Pausova Z, Uher R, Alda M, Spaniel F, Hajek T. Obesity, dyslipidemia and brain age in first-episode psychosis. $J$ Psychiat Res, 2018; 99:151-158.

[43] Spangaro M, Mazza E, Poletti S, Cavallaro R, Benedetti F. Obesity influences white matter integrity in schizophrenia. Psychoneuroendocrino 2018; 97:135-142.

[44] Zhao Z, Okusaga OO, Quevedo J, Soares JC, Teixeira AL. The potential association between obesity and bipolar disorder: A meta-analysis. J Affect Disorders, 2016; 202:120-123.

[45] Islam AH, Metcalfe AWS, MacIntosh BJ; Korczak DJ, Goldstein, BI. Greater body mass index is associated with reduced frontal cortical volumes among adolescents with bipolar disorder. J Psychiatry Neurosci 2018; 43(2):120-130.

[46] Chouinard V-A, Pingali SM, Chouinard G, Henderson CD, Mallya SG, Cypess AM, Cohen BM, Öngür D. Factors associated with overweight and obesity in schizophrenia, schizoaffective and bipolar disorders. Psychiatry Research, 2016; 237:304-310.

[47] British Broadcasting Corporation (BBC). Statistics reveal Britain's 'Mr and Mrs Average. 3 October 2010, Available at: https://www.bbc.co.uk/news/uk-11534042.

[48] Medcalc. Significance of one proportion. 2018 [Online] Available: https://www.medcalc.org/calc/test_one_proportion.php

[49] Brown School of Public Health. Open Meta-Analyst. 2018; [Online] http://www.cebm.brown.edu/openmeta/download.html.

[50] National Health Service. BMI Calculator. 2018 [Online] Available: https://www.nhs.uk/Tools/Pages/Healthyweightcalculator.asp $\mathrm{x}$

[51] Moorse JM, and Niehaus L. Mixed method design: Principles and procedures. London and New York: Routledge; 2009.

[52] Tashakkori A, Teddlie C. (Eds.) (2003). Handbook of mixed methods in social and behavioural research. Thousand Oaks, California: SAGE; 2003.

[53] Schifferdecker KE, Reed VA. Using mixed methods research in medical education: Basic guidelines for researchers. Med Educ, 2009; 43:637-644.

[54] Haidich AB. Meta-analysis in medical research. Hyppokratia, 2010; 14 (1):29-37.

[55] Nordmann AJ, Kasenda B, Briel M. Meta-analyses: What they can and cannot do. Swiss Medical Weekly, 2012; 142.

[56] Rosendaal FR, Reitsma PH (2014). Meta-analysis. Journal of Thrombosis and Hemostasis, 2014; 12:1009.

[57] Fernandes J, Ferreira-Santos F, Miller K, Torres S. Emotional processing in obesity: a systematic review and exploratory meta-analysis. Obes Rev, 2018; 19:111-120.

[58] Eggerm M (1997). Meta-analysis: principles and procedures. BMJ, 1997; 315:1533.

[59] Cook DA. Randomized controlled trials and meta-analysis in medical education.: What role do they play? Med Teach, 2012; $34: 468-473$.

[60] Ishak KJ, Platta RW, Joseph L, Hanley JA, Caroa JJ. Meta-analysis of longitudinal studies. Clin Trials, 2007; 4:525539.

[61] Zhang D. A coefficient of determination for generalized linear models. Am Stat, 2017; 71(4):310-316.

[62] Magnusoon K. Interpreting correlations: An interactive visualization. 2018 [Online]. Available: http://rpsychologist.com/d3/cohend/

[63] Lenhard W, Lenhard A (2016). Calculation of effect sizes. Psychometrica, 2016; Available: https://www.psychometrica.de/effect_size.html.

[64] Lyons-Morris AM. Meta-Analysis. 2018 [Online]. Available: $\mathrm{http}: / / \mathrm{www}$. lyonsmorris.com/ma1/

[65] Cohen J. Statistical power analysis for the behavioral sciences. Hillsdale, NJ: Erlbaum; 1988.

[66] Magnusoon K. Interpreting Cohen's d effect size: An interactive visualization. 2018. [Online] Available: http://rpsychologist.com/d3/cohend/

[67] World Health Organisation. Physical status: the use and interpretation of anthropometry - report of a WHO Expert Committee. WHO Technical Report Series No. 854, World Health Organisation, Geneva; 1995.

[68] Raben AT, Marshe VS, Chintoh A, Gorbovskaya I, Daniel Müller DJ, Hahn MK. The complex relationship between antipsychotic-induced weight gain and therapeutic benefits: A systematic review and implications for treatment. Front Neurosci-Switz, 2018; 11: Article 741.

[69] Lin C-H, Lin S-C, Huang Y-H, Wang F-C, Huang C-J. Early prediction of olanzapine-induced weight gain for schizophrenia patients. Psychiatry Research, 2018; 263:207-211.

[70] Marques C, Meireles M, Faria A, Calhau C. High-fat diet-induced dysbiosis as a cause of neuroinflammation [Letter to the editor]. Biol Psychiatry, 2016; 80:e3-e4.

[71] Peet M, Stokes C. Omega-3 fatty acids in the treatment of psychiatric disorders. Drugs, 2005; 65(8):1051-1059.

[72] Bruce-Keller AJ, Keller JN, Morrison CD. Obesity and vulnerability of CNS. Biochim Biophys Acta, 2009; 1792:395-400.

[73] Opel N, Redlich R, Grotegerd D, Dohm K, Heindel W, Kugel $\mathrm{H}$, Arolt V, Dannlowski U. Obesity and major depression: Body-mass index (BMI) is associated with a severe course of disease and specific neurostructural alterations. Psychoneuroendocrino, 2015; 219-226. 